\title{
DONOSO CONVERSA CON DONOSO SOBRE LA POSIBILIDAD DE ESCRIBIR LA "GRAN NOVELA DEL GOLPE”: EL JARDÍN DE AL LADO*
}

\author{
Grínor Rojo \\ Universidad de Chile \\ grinorrojo@hotmail.es
}

RESUMEN / ABSTRACT

Este artículo aborda El jardín de al lado como una novela sobre la condición del escritor chileno en el exilio. Su protagonista es un novelista mediocre, Julio Méndez, quien ha salido del país después de pasar seis días en un calabozo, donde "no me torturaron ni me interrogaron siquiera", pero que sin embargo fueron "como el trazo que definía el contorno de mi identidad". A partir de esa experiencia irónicamente traumática, Méndez decide escribir la gran "novela del golpe". Fracasa él, pero no quien cuenta su historia, José Donoso, el que, aun cuando en El jardín de al lado no haya producido la mejor de sus novelas, generó con ella un texto valioso, a medias autobiográfico y a medias ficción y metaficción, y en el cual ensaya un argumento polémico acerca de la literatura chilena que se vincula a los sucesos posteriores al 11 de septiembre de 1973 .

Palabras Clave: arte y dictadura, literatura chilena en el exilio, ideología y arte, autobiografía, ficción y metaficción.

This article deals with El jardin de al lado understood as a novel about the condition of the Chilean writer in exile. The protagonist is a mediocre novelist, Julio Méndez, who has left the country after spending six days in prisson, where "they did not torture me, or even interrogate me", but it became however "the mark defining the contours of my identity". Based on this ironically traumatic experience, Mendez decides to write the "great novel of the coup". He fails, but not so the one who tells his story, José Donoso, who, even though has not produced

Proyecto Fondecyt 1120038, "Las novelas de la dictadura chilena" (1973-2011). 
the best of his novels with El jardin de al lado, has generated with it a valuable text, half autobiography and half fiction and metafiction, and in which he elaborates a controversial argument about Chilean literature connected with the events that followed September 11 of 1973.

KEY WORDS: Art and dictatorship, Chilean literature in exile, Ideology and art, Autobiography, Fiction and metafiction.

Concedido: El jardín de al lado no es la mejor novela de José Donoso, pero es una novela interesante y hasta estoy dispuesto a admitir que el interés que yo tengo en ella se debe precisa y paradójicamente a este hecho, a que no es la mejor de las novelas donosianas. Es, en cambio, un texto a medias autobiográfico y a medias ficticio, provisto de una referencialidad que a mí me parece necesaria para los fines que Donoso se propuso con él, fines que la ficción encubre apenas, y quien quiera que haya leído la Historia personal del 'boom', de 1972, y Conjeturas sobre la memoria de mi tribu, de 1996, o Correr el tupido velo, el libro testimonial de la hija adoptiva de Donoso, Pilar, de 2011, sabrá de qué estoy hablando. Me explico: El jardín de al lado nos ofrece un inventario completo, redondo, casi exhaustivo, diría yo, de las preferencias, las manías, las fobias, las angustias, los rencores y los terrores, los gustos y los disgustos, las malignidades infantiles y adultas, la esnobería, la cursilería, la hipocondría, las envidias, el clasismo y el racismo, la mala leche en definitiva, pero asimismo de algunas de las más sagaces intuiciones del escritor José Donoso, puesto éste en la para él incomodísima circunstancia de replantearse su vida y su práctica literaria vis-à-vis los desmanes de la dictadura que gobernó Chile a sangre y fuego a partir del 11 de septiembre de 1973. Como intelectual, como artista chileno, mi sospecha es que Donoso sintió que tenía que pronunciarse frente a tales sucesos. El problema era en qué podía consistir ese pronunciamiento y cómo objetivarlo en su quehacer, aunque sin traicionar con ello las esencias de la que él estimaba era una vocación no negociable. Este es el quid de su novela. Todo en ella arranca de ahí y ahí es donde al fin de cuentas va a parar.

Por lo mismo, desde el punto de vista de los contenidos, El jardín de al lado es una novela a la que uno puede poner con facilidad en el casillero de las "novelas de artista" o "novelas de escritor", de larga y copiosa incidencia en la historia de la literatura latinoamericana desde que en el modernismo las introdujeran por primera vez entre nosotros autores como Pedro César Dominici, Manuel Díaz Rodríguez, José Asunción Silva, José María Rivas Groot y Ángel de Estada. Recurrente en estas novelas es la contradicción 
entre el querer hacer y el hacer, entre el deseo de producir "bellas letras" y las dificultades, tanto las sociales como las personales, que en el mundo moderno se le interponen a aquellos que pretenden hacer suyo el programa respectivo: "fueron dos autores románticos Wilhelm Heinse (1746-1805)-fue representante del Sturm und Drang, cuya estética constituyó un elemento del romanticismo- y Friedrich Schlegel (1772-1829), quienes en sus novelas Ardinghello y las islas bienaventuradas (1787) y Lucinde (1799) trazaron los perfiles del artista como 'genio' (Heinse) o como marginado rebelde y afirmativamente consciente de esa marginación (Schlegel), y al mismo tiempo convirtieron al artista en objeto novelable, es decir, crearon la 'novela de artista"" (Gutiérrez 54).

Con esto solo quiero decir que la temática que aborda Donoso en El jardín de al lado no es en sí misma deslumbrantemente novedosa. Somos testigos en su novela de las andanzas de un individuo, Julio Méndez, un chileno cincuentón y sin demasiado talento, que quiere ser novelista y más todavía, que quiere ser un gran novelista, pero sin contar con las condiciones tanto externas como internas que hacen falta para eso. Ha tenido con algunas de sus tratativas previas un estreno modesto, si bien promisorio, un éxito "nacional" (se nos informa que es autor de dos novelas y un libro de relatos y que ha sido objeto de una crítica elogiosa de parte de Hernán del Solar, aunque también se nos advierte que Alone guardó sobre la novela un significativo silencio) $y$, después de una estancia de seis días en "un calabozo a raíz del Once, donde no me torturaron ni me interrogaron siquiera", pero que sin embargo fueron "como el trazo que definía el contorno de mi identidad" (Donoso, Jardín 32-3), descubre la veta que podría transformarse en su "pasaporte al triunfo", el que le permitirá finalmente "salir de la sombra" (33), por lo que para explotarla con la independencia y el celo que ella requiere se convierte en un "exiliado voluntario". Parte por eso a España, a Cataluña, para ser más exacto, a las ciudades de Barcelona y Sitges, en compañía de su mujer, Gloria, y de su hijo, Patricio ("Pato"), el que allí crece y no tarda sacarse de encima a sus padres, entre otras insubordinaciones reemplazando su nombre tan siúticamente chileno de Patricio por el anglofrancés de Patrick: "dice que se nos quedó pegado el disco de la UP y del Once, que no sabemos hablar de otra cosa que de Allende y de la DINA, puras huevadas, dice, a nadie de mi edad le importa un carajo ese rollo" (28).

La opción geográfica no tiene nada de azarosa, por lo demás. Cuando los Méndez aterrizan en Barcelona ésta es una ciudad caliente aún, aunque comenzando ya a enfriarse, con el marqueteo sesentero de los escritores 
latinoamericanos del boom $^{1}$. De ahí que, según discurre el aspirante chileno a gran escritor, constituya el lugar perfecto para que él sobreponga su nombre a los de la para él injustificadamente prestigiosa plantilla de los integrantes de ese grupo: "¿novela-documento que, aunque ya rechazada una vez por la formidable Núria Monclús, yo estaba seguro de poder transformar en una obra maestra superior a esa literatura de consumo, hoy tan de moda, que ha encumbrado a falsos dioses como García Márquez, Marcelo Chiriboga ${ }^{2}$ y Carlos Fuentes?" (15).

Méndez es, como vemos, uno de los "detractores" del boom, a los que Donoso se refiere ambivalentemente en las páginas iniciales de su Historia..., los que lo admiran al mismo tiempo que lo vilipendian y, al cabo, ansían desbancarlo. Para eso, su intención es hacer uso de la carta de triunfo que trae escondida debajo de la manga, aplicar sus escasos aunque pretenciosos talentos a la escritura de la "novela del golpe". Pero ocurre que para dar cumplimiento a este propósito emplea más años de los que conviene, siete en total, y cuando por fin pone término a la obra el interés de los europeos por los crímenes del pinochetismo está en franca declinación: "mi gran experiencia chilena iba retrocediendo, desgastada por los años su función como fuente de elocuencia" (33).

Produce de todos modos un primer manuscrito, que la célebre Núria Monclús (el nombre con que Donoso disfraza a la legendaria Carmen Balcells. En éste y en otros puntos del relato, la novela de Donoso se torna en un roman a clèf y una de las vías menos recomendables para comentarla pudiera consistir en perseguirlos) rechaza, y a continuación un segundo, que según el criterio de esa misma y todopoderosa señora es aun peor que el anterior: "hipertrofiada, enferma, declamatoria, chillona", son la palabras exactas con que ella condena la laboriosa reescritura de Méndez (226).

1 En su Historia personal del 'boom', Donoso fija las fechas de nacimiento y muerte de este fenómeno literario entre dos fiestas: "la anécdota del boom como tal comienza en aquella aparatosa fiesta en la casa de Carlos Fuentes en 1965 [...] y para mi ver termina como unidad, si es que la tuvo alguna vez más allá de la imaginación y si en realidad ha terminado, la noche vieja de 1970, en una fiesta en casa de Luis Goytisolo, en Barcelona". Sin embargo, reconoce poco después que el golpe de gracia fue el affair Padilla, de 1971 (Donoso 87).

Marcelo Chiriboga, escritor ecuatoriano apócrifo, al que se le atribuye un éxito enorme y que aparece no solo en este libro de Donoso, es la figura en cuya consideración él condensa la ambivalencia, la mezcla de admiración y desconfianza, que le producen los corifeos del boom. 
Consecuencia de ese segundo y definitivo desengaño es el arrebato que hace presa de su espíritu, que lo lleva a robar un cuadro de alto precio (eco de un acto previo protagonizado por otro personaje de la novela, Bijou, de quien ya hablaré) y a emprender con el dinero de la venta un viaje a Tánger, acompañado de un descenso ahí (en rigor, de una intentona de descenso; tampoco eso le funciona bien del todo al pobre) a sus pecaminosos infiernos. En la novelística de la modernidad, ésa es una peripecia tópica por cierto, aquí en deuda flagrante con la asidua frecuentación por parte de Donoso de los narradores angloamericanos del imperialismo, de Forster a Lowry y a Bowles (The Sheltering Sky de este último está aludido en el texto específicamente. Una película de Louis Malle, de 1992, Damage, termina con el Dr. Stephen Fleming, un personaje que actúa Jeremy Irons, de anacoreta en algún pueblo perdido del Mediterráneo, habiendo hecho un periplo que podría compararse con éste de Méndez), y que él le da el pie para concluir el primero de los dos finales de su novela. Con todo, si los ponemos al uno junto al otro, el ademán de extravío que protagoniza el chileno con la fundada potencia de los de sus predecesores metropolitanos, quienes, como es sabido, tenían el hábito de poner en jaque a su cultura exhausta perdiéndose sin miedo entre los sabrosos aun cuando letales meandros de las "razas inferiores" y sus "dioses oscuros", nos daremos cuenta de que el protagonista de El jardín de al lado se queda una vez más en los bordes. La ironía donosiana es en ello ostensible y bienvenida: su agudeza de buen escritor se percató, no pudo menos que percatarse, de la incongruencia irrisoria que estaba ligada a la imitación, chilena y latinoamericana, del tópico central. De "odisea bufa" la califica Oscar Montero y creo que tiene razón ${ }^{3}$.

Pero antes de eso Donoso echa mano del equívoco aforismo del "jardín de al lado", él que siempre es mejor que el jardín propio, y de donde proviene el título de la novela. Perseguidos por sus numerosas insatisfacciones, por sus peleas "enconadas" y por el consumo inmoderado de coñac y de Valium, Julio y su mujer se mudan entre junio y agosto de 1980 a un lujoso

\footnotetext{
Oscar Montero. "El jardín de al lado: la escritura y el fracaso del éxito". Revista Iberoamericana 123-124 (1983), 450. Metáfora prístina de la incongruencia a que aquí me refiero es la comparación del magnifico ciprés del duque con el ciprés chileno que alguna vez plantó Méndez en Chile: "Contemplo aquel ciprés, recordando cómo, al codiciar uno igual, a los dieciocho años planté un ciprés en el jardín de la casa de la calle Roma, pero al cabo de pocos años fue necesario pedirle al jardinero que lo cortara porque creció sin forma, ralo, desharrapado, un vegetal que en su breve historia nada tuvo en común con la elegancia europea" (69).
} 
"piso" madrileño, préstamo veraniego de un amigo de infancia de Méndez, el exitoso pintor Pancho Salvatierra, ubicado en el corazón de la ciudad y cuyos grandes ventanales se abren sobre un "palacete" y un "jardín" que, la verdad sea dicha, son mucho menos castizos que sacados de las ilustraciones que en los años treinta y cuarenta dibujaba Coré para los niños lectores de $E l$ Peneca chileno. Es un jardín de cuento de hadas, por lo tanto, perteneciente a un tal duque de Andía, un "Grande de España" (20), en cuyo centro reina su rubia nuera austríaca, que es casi un efebo: una baronesa "de nombre impronunciable" (98), convertida en España en condesa De Pinell de Bray. En la escena siguiente, desde el escondite que le proporciona la penumbra de su ventana, como antes que él lo hiciera L. B. Jeffries (Jeff), el fotógrafo voyeur de Hitchcock en Rear Window, el Julio Méndez de Donoso contempla a la joven condesa en toda su dorada y esbelta magnificencia, cuando ella se deja ver en el jardín rodeada por la corte de sus pajes y dando forma así a una paisaje de cultura "aristocrática" en cuya confección, además de Coré, se amontonan, explícita o implícitamente, el Rubén Darío de Prosas profanas..., el Keats de la Ode on a Grecian Urn, El abrazo de Klimt, el Matisse de la Danza, las esculturas estilizadas de Brancusi (¿o serán las de Giacometti?), L'après midi d'un faune de Mallarmé et al., el Gatsby de Scott Fitzgerald, la duquesa de Guermantes de Proust y la Alicia de Lewis Carroll:

Sortilegio es una palabra desprestigiada, ya lo sé, pero debo usarla: de golpe, el sortilegio radiante del exterior avasalla y suplanta mi pobre realidad $[\ldots]$ Son tres muchachas y tres muchachos, ellas de bikinis brevísimos bajo pareos anudados a la cintura o al cuello, ellos con pantalones de baño. Traen copas, un plato de postre, el café en la mano, charlan, ríen un poco. Están contentos. Todos, tanto ellas como ellos, parecen construidos en forma esencial, por eliminación de todo lo superfluo, como por Brancusi. La plenitud sexual es directa, una especie de elasticidad o libertad de movimientos, que parece ponerlos en contacto instantáneo con todo lo que los rodea, y unos con los otros: forman un friso rítmico de cuerpos estilizados al que no le le falta ningún atributo de lo masculino o lo femenino [...] Ella está ahí: la campana de oro, la más Brancusi y dorada y pulida de todas, con sus gestos largos que nada tienen de indolente y la jaula de sus costillas y la escueta suavidad de la pelvis revelada por el brevísimo bikini, transfigurada en un esmerilado objeto de lujo [...] Bailan a la luz de los focos, casi desganadamente, reflejados en el agua, cambiando pareja sin que cese o cambie, al parecer, la música, sin tensión ni esfuerzo [...] Esa intimidad..., esa espalda partida, cuya línea y resplandores 
oscilan apenas con el ritmo, y la seguridad con que [él, el acompañante de la joven] conduce a su pareja en el abrazo: siento el peligro de su atracción, y quisiera meterme dentro de él, ser él, tener la delgadez de la rubia, cuya cabeza cae sobre su hombro cubriéndolo de oro, envuelta en mis brazos; sí ser él para cambiar mis códigos y problemas, como este ardor en el estómago que me produce el desacostumbrado Curvoisier, sí, borrar mis huellas y huir en busca de otro superego o, mejor, ninguno, sólo el placer. ¡Ah! ¡El esplendor... la vieja nostalgia desgarradora de tiempos y cuerpos imposibles! ¡La parte Gatsby, Scott Fitzgerald, del mundo de acceso imposible, la terrible fiesta a la que no fui invitado y que sólo es posible soñarla desde afuera! ¡Ah fantasía infantil del terror de quedar excluido! (106-108).

Me he extendido más de la cuenta en la cita de este pasaje y espero que el lector me disculpe, ya que me parece importante para el análisis que aquí pretendo ofrecer de la novela de Donoso. No debe sorprender a ese lector, desde luego, que éste sea un pasaje gráfica y estratégicamente colocado casi en el centro de su libro, contenedor allí de lo que su disfrutante caracterizará después, en el recuerdo, como una "noche portentosa" (115), pues fija el punto donde se originan y desde donde proliferan los círculos de sentido que alimentan el despliegue sintagmático del discurso novelesco. Se entiende que a Méndez le resulte más seductora la imagen que está teniendo en ese instante frente a los ojos que las menos "esenciales", menos "libres", menos "plenas", pero sí más encardinadas y repulsivas, que él ha venido compulsando hasta el agotamiento tanto en la disfuncionalidad de su vida cotidiana como durante la redacción de la novela "del golpe" que tiene entre manos. Después de admirar el "sortilegio" del "jardín de al lado", descuida aquel proyecto suyo indefectiblemente: "Hace días que no trabajo [...] No estoy para novelas políticas que hablen de la esperanza de la vuelta a una democracia parlamentaria como la de mi padre, que es lo que de mí debe esperar tanto Chiriboga como Adriazola, sino para endechas dirigidas a una castellana medieval" (148).

Pero tampoco esa fantasía es lo que es y nada más: si bien es cierto que por una parte constituye un escape por contraste respecto de la "pobre realidad" en la que este sujeto sobrevive a los rezagos y decepciones de su exilio, es decir a las que en la cita de arriba él identifica como sus "códigos" y sus "problemas", y por otra de la espinosa realidad de la que voluntariosamente pretende hacerse cargo con la ayuda de su escritura, en un desplazamiento ulterior (uso este término con su significado freudiano y lacaniano) también es un sustituto ("suplemento" es la palabra que habría empleado Derrida) 
para el ámbito familiar y social de privilegio del que ahora carece, el que se le quedó atrás en su pasado chileno y al que añora pero al que no desea volver. Me refiero al "jardín" de la infancia, al de su "casa" solariega de Chile, la de la calle Roma, en cuyo centro reinó su madre, ahora moribunda $\mathrm{y}$ que fallece en efecto durante el transcurso del relato:

Cuando se termine esa casa ya no tendré donde volver. ¿Ni para qué volver? Uno sueña con el regreso a su país, abstracción materializada más que por lo fortuito del lugar de nacimiento, porque el sueño del regreso se refiere a cierta ventana que da a cierto jardín, a un tapiz de verdes entretejidos de historias privadas que iluminan relaciones de seres y lugares: éstos configuran el cosmos que hice nacer en el jardín al que ahora me asomo, hace ya más de medio siglo (68).

¿Tengo que decir que la mujer-efebo del jardín de al lado morirá también, a causa de un "inexplicable suicidio" (254), pero en el fondo por ninguna otra motivación que no sea la de su obediencia para con el paralelismo entre el recuerdo ideológico y la fantasía estética que se apoderan de la conciencia de Méndez y que son el fundamento del debate de "poéticas" que es el principal empeño de Donoso en esta novela? En ambos casos se trata de mujeres que están en el centro de la imagen en la cual se hallan insertas y en ambos casos su muerte testimonia el resplandor de una pérdida. No solo eso, ya que en el revés de la condesita de Pinell de Bray se guarda también, según nos lo deja saber el narrador en el capítulo tercero, una muy hispánica "madraza" (115). Porque lo cierto es que si al oligárquico jardín de allá se le superpone el palaciego jardín de acá ello es debido a la puesta en marcha de un mecanismo a la larga interrupto de sublimación:

me levanto de la cama y miro: sí, un jardín. Olmos, castaños, tilos, un zorzal -o su equivalente en estas latitudes-; no me propongo aprender su nombre porque ya estoy viejo para integrarlo a mi mitología personalsaltando sobre el césped no demasiado cuidado: el duque es un gandul. La formalidad con que las espadas de los lirios desfilan a lo largo del muro casi velado por el boscaje. Florecillas inidentificables brotan a la sombra de las ramas - ijuncos?, ¿cinerarias? No, ésas son flores de comienzos de primavera, pues mijito, y estamos a comienzos de junio aunque allá en España la primavera recién acaba de terminar-, parecida a la sombra de las ramas de un jardín de otro hemisferio, jardín muy distante a este pequeño parque aristocrático, porque aquélla era sombra de paltos y araucarias y naranjos y magnolios, y sin embargo esta sombra es igual a aquélla, que rodea de silencio 
esta casa en que en este mismo momento mi madre agoniza (67, el subrayado es mío, G. R.).

Una doble realidad insatisfactoria es la que ocupa el primer plano de esta novela de Donoso, en consecuencia, la realidad de una vida personal y social que se habría visto dislocada por el acontecer histórico, ya que se nos sugiere que ese acontecer histórico es el que impide que Méndez desarrolle su proyecto de vida y de arte como a él le gustaría, a la que se le superpone la difícil nostalgia del domus materno, familiar, patrio y protector ("baluarte de las tradicionales estructuras que nos identifican" [122]), y a la cual se le superpone en un tercer nivel un espacio absoluto, de carácter armónico, donde las diferencias, por lo pronto las sexuales, desaparecen: la mujer-efebo, que luego se replica en Bijou, el "angelo musicante", un adolescente de una "blanca delicadeza, infantil, casi femenina" (61), que se pasea por el relato de principio a fin. De hecho, la aspiración suprema del voyeur de El jardín de al lado es a la no identidad, a un barrer muy postmoderno con la historia de sus "huellas" y, si es que no vuelve a Chile, la verdadera razón es que "allá no aceptan que persona sea sinónimo de máscara, una de mis tantas máscaras que aquí puedo cambiar libremente" (76). Porque ésa es la promesa del espacio "creado" por el arte puro, la promesa de un espacio "libre", según el modelo que va de Darío a Coré y a Lewis Carroll, y que apunta no al cómo las cosas son sino al cómo tendrían que ser. He ahí entonces el espectáculo, y chapeau para Donoso a este respecto, de un proceso en el que nítidamente a la realidad la cancela la ideología y en el que a posteriori a la ideología se la sublima o se la trata de sublimar por medio de los esfuerzos esencializadores, pero también universalizadores, desidentificadores más bien, del arte. Las resonancias, los "ecos", como le gustaba decir al maestro Borges, ya sea por tesis o por antítesis, alcanzan en este punto de El jardín de al lado su expresión máxima y se multiplican hacia atrás y hacia adelante del texto, de maneras diversas y con intenciones afines, en la misma medida en que el flujo narrativo progresa.

Me referí de paso a la cuestión sexual: Bijou, el ubicuo angelo musicante que obsesiona al madurón Méndez y que como dije es uno entre los varios ecos de la reina Mab del jardín de al lado, es quien la hace efectiva, y ello en tanto constituye la encarnación de una "plenitud" que no se restringe a un solo signo genérico, que es masculina y femenina a la vez, que el escritor anhela para sí, pero que sus "códigos" le prohíben. Una vez más, se trata de un clisé conocido y respecto del cual se cita en la novela la relación VerlaineRimbaud, pero del cual yo creo que el Tadzio de La muerte en Venecia, sobre 
todo en la versión de Visconti, con el enclenque y contrito Dirk Bogarde haciendo de Aschenbach, resulta más apropiado.

Más importante me parece, sin embargo, el contraste entre la situación menesterosa de Méndez y el éxito público y la opulencia pecuniaria de su magnánimo amigo Salvatierra. $\mathrm{O}$, mejor aún, entre el proyecto de arte "comprometido" del primero y la frivolidad social y política del segundo:

En el mundo de Pancho, en cambio, las cosas son ingrávidas, gratuitas: carecen de historia, de causas, de futuro [...] Puritano receloso del placer en que me ha transformado nuestra historia reciente, al principio lo rechacé todo, incapaz de soportar a Pancho: ira, sin duda, un componente de envidia, una condena, digna de Adriazola por la alienación en esas cosas, censura a su culpable indiferencia a los problemas del mundo y de Chile, repulsión por su egoísmo o egocentrismo, por su frivolidad, todo eso en contraste inexplicable y turbador con su hondura como artista: el sentido del humor, que era casi como una marca de fábrica en gente como uno, anulado después del Once, ¿Por qué - me preguntaba cada vez que hablaba con él, cada vez que veía su casa o su pintura-, por qué Pancho tenía la terrible virtud de replantearme el problema, que yo ya daba por resuelto, de la relación entre arte y ética? (17 y 20).

$[\ldots]$

¿Es ése, medito fugazmente, el secreto del éxito de Pancho? ¿Esa capacidad de producir una reacción instantánea, subliminal, con su arte envolvente y seductor, en que el placer es lo primero? Poseer un punto de vista tan original que se acerque a lo cómico..., pienso en Dalí, en Chirico, en Magritte, que también son envolventes, instantáneos y divertidos. ¿Es eso lo que ansío tener, que Marcelo Chiriboga sin duda posee y yo no? (144)

Nos queda claro que al autor no tan implícito de El jardín de al lado ninguna de las dos opciones estéticas ejemplificadas aquí, ni la de Salvatierra ni la de Méndez, le parece reclamable para su propio consumo, aunque también nos quede claro que la de Salvatierra es la que se encuentra más cerca de sus preferencias. Y es que el pasaje que yo acabo de citar no tiene otra finalidad que la de introducir en la trama de la novela de Donoso una oposición binaria que es la de mayor envergadura entre aquellas que a la manera de círculos concéntricos rodean a la oposición básica, la que identifiqué más arriba, y que se establece entre el jardín de al lado y su voyeur. Me refiero en este otro 
caso a la coextensiva, que enfrenta un proyecto de arte y de literatura "puros" al "voluntarismo documental" de los realistas sociales. Hasta los adjetivos se parecen: si la apariencia de la mujer del jardín es "esencial", habiéndose eliminado de ella todo lo que era "superfluo", la de la pintura del pinochetista Salvatierra es "ingrávida".

Un contraste del mismo tipo, en este caso en torno al grado del "compromiso", se observa entre Méndez y el pintor Adriazola. Estando los dos equivocados, el más equivocado de los dos es, sin ninguna duda, Adriazola:

Este extraordinario pintor de protesta, sobre el que por ese tiempo aparecían reportajes en colores en algunas revistas. Este hombre-que vivía en Europa desde mucho tiempo antes de la UP y del golpe-, se había adueñado de un largo muro que bordeaba la carretera por donde pasaba todo el tráfico turístico que baja desde Francia y los países del norte, dirigiéndose a las playas del Levante y de la Costa del Sol. En ese muro, con veinte o más discípulos de todas las nacionalidades, edades y sexos, todos entusiastas de la causa de la libertad, pintaban interminables murales en que figuraban, entre sangre y charreteras, golpistas y golpeados, y como si no fuera clara la intención, pintaban frases que no permitieran dudas [...] Fue esa comercialización demasiado evidente del mesiánico quehacer de Adriazola y el oportunismo transparente de su retórica revolucionaria, lo que, al cabo de una semana de permanencia en Vendrell, me hizo separarme de él y no de muy buen modo, y buscar mis propias matizaciones refugiándome en el cercano Sitges, que me pareció más tranquilo, y que alojaba a personas con persuasiones políticas menos terminantes (49).

En suma: tres estéticas en conflicto dentro del mundo narrado que Donoso nos presenta en El jardín de al lado, cuyo año de composición (¿casualmente?) coincide con el año del apogeo de la dictadura, 1980, cuando Pinochet inaugura su etapa "constitucional". Ninguna de ellas deja contento a su protagonista, sin embargo: la primera, que es aquella en la que Méndez quisiera embarcarse pero no puede, es la de los narradores del boom, a los que vilipendia pero en el fondo resiente y envidia ${ }^{4}$; la segunda, que es la de

4 Montero, a quien cité anteriormente, conecta esta actitud de Méndez para con los corifeos del boom a la de Donoso en su Historia personal del boom. Según él, en ambos, el personaje y el escritor, la llegada es tardía y la posición automarginada. 
Adriazola, le resulta intolerable en la medida en que sacrifica las demandas del arte a un compromiso social y político grosero, panfletario, oportunista e inclusive corrupto, al menos a juicio de Méndez; y la tercera, que es la de Salvatierra, desestima el compromiso social y político y se inclina por un arte "ingrávido", "gratuito", que carece "de historia, de causas, de futuro". Esta última es una postura que a Méndez lo atrae, pero respecto de la cual no deja de tener y de manifestar, como se ha visto, ciertas pudorosas reservas: "culpable indiferencia a los problemas de Chile y del mundo", etc.

Planteado con esta sencillez rudimentaria (no quiero escribir simplismo, pero lo voy a escribir de todos modos), el de Julio Méndez es un problema sin salida, o sea que es un problema que no tiene salida en él, en los angostos callejones conceptuales por los que, con más o menos lucidez, su conciencia atribulada circula y menos aún en la práctica de su escritura tal y como él la ha programado, tal y como se la ha estado imponiendo empecinadamente desde los lejanos seis días de su epifanía carcelaria. Méndez se queda de este modo sin nada que no sea su frustración, su sensación de "mediocridad" y de "fracaso", éstas tal vez las dos palabras que más se repiten a lo largo de un discurso narrativo en primera persona, autodiegético y simultáneo, aunque en el último capítulo cambie o salga a la superficie una segunda voz, como pronto se verá. Son los términos que Donoso escoge para caracterizar a su protagonista o, mejor dicho, para que su protagonista se autocaracterice: como un perdedor sin remedio. Un perdedor que sin embargo es dueño de la suficiente clarividencia como para saber que lo es, aunque a ratos se ilusione con la expectativa de un "breakthrough" (48). Reflexiona sobre las limitaciones de su opera magna:

Y la vi, mi frondosa, sentimental, autocompasiva, aburrida novela. Al comienzo tomaba notas con cierto desgano que no excluía la esperanza. Pero tengo un hábito de lector entusiasta, especialmente de novela contemporánea, asignatura que enseño, o más bien que enseñaba: así, al avanzar por mi copioso escrito se me fue haciendo indudable que la pasión que pretendía animarlo no era ni convincente como literatura ni válida como experiencia (116-117).

En otro nivel, sin embargo, que ya no es el del personaje protagónico sino el del autor implícito de El jardín de al lado y, estimo yo, también el de su autor histórico, el "problema" estético de Méndez sí se resuelve. No en aquello que se mira sino en quien lo mira $y$ desde afuera. El narrador protagonista habla y da cuenta de su vida y su proyecto, en tanto que el autor implícito, ése 
que para nosotros los lectores solo existe por implicación connotativa, pero cuyo comentario sentimos constantemente en nuestro oído (e incluyendo al autor histórico, ya que no hay distancia entre uno y otro), se burla de él. Él ha podido hacer lo que Méndez no puede: escribir la novela, esta novela, la que estamos leyendo. Una novela que, como ya lo dije, es interesante, aunque no sea una de las mejores de Donoso, y cuyo asunto son las agonías de un hombre que ha sido incapaz de escribirla.

Por aquí es por donde yo siento que El jardín de al lado se configura como un texto entre referencial y ficcional. Más precisamente: como una "novela autobiográfica", de esas que confundían a Phillipe Lejeune porque escapaban al "pacto autobiográfico", a la identidad del autor con el narrador y el protagonista, cualquiera sea la definición que se le dé (y en Lejeune hay dos por lo menos, una positivista y una semiformalista), introduciendo elementos ficticios (o no pactados como verdaderos sino como verosímiles. Con el tiempo, Lejeune se percató de que el "yo" del texto autobiográfico era o podía ser tan ficticio como el del texto ficcional y que la diferencia consistía más bien en los términos verosímiles en que el "pacto" se efectuaba). Novela autobiográfica, entonces, pero a contrario modo. En definitiva, habría que concluir que El jardín de al lado es un texto autobiográfico porque Donoso está en él de cuerpo entero y sin inhibiciones, y más con sus deméritos que con sus méritos, como yo lo hice presente en el párrafo con que di comienzo a este ensayo y como puede corroborarse recurriendo a las Conjeturas sobre la memoria de mi tribu o a los otros dos libros que mencioné al principio de mi trabajo, aunque no sea una autobiografía en sentido estricto, pues estamos hablando en esta oportunidad de un discurso en el que no solo no coinciden las voces de "autor y sujeto de la enunciación (o 'narrador')", según lo precisa Leonidas Morales, sino de uno en el que el narrador protagonista es el receptáculo de las dudas y los terrores del autor (11). Quiero decir que Méndez es una contrafigura de Donoso, que es esa identidad personal y artística que Donoso construyó como su alter ego posible pero indeseable, rodeado y forzado a tomar una "posición" de entre aquellas (o de entre la opciones de "posiciones", es lo que diría Bourdieu ${ }^{5}$ ) que el campo literario chileno

\footnotetext{
"en fase de equilibrio, el espacio de las posiciones tiende a imponer el espacio de las tomas de posición: las transformaciones profundas del espacio de las tomas de posiciones, las revoluciones literarias o artísticas, sólo podrán resultar de las transformaciones de las correlaciones de fuerza constitutivas del espacio de las posiciones, transformaciones mismas que son posibilitadas por el encuentro entre las intenciones subversivas de una fracción de
} 
de la época de la dictadura le planteaba con urgencia ética, pero tratando de no favorecer a ninguna. Exorcizar el peligro de dar un paso en falso, de olvidarse de sí y de su proyecto entregándose a los riesgos de una causa a lo mejor muy decente, pero cuya materialización literaria a él le resultaba difícil de procesar y que lo habría anulado como el escritor que venía siendo y que no estaba dispuesto a dejar de ser en el futuro, era pues una necesidad y su novela fue la encargada de cumplir con ese cometido.

Leonidas Morales, quien, siguiendo a Peter Bürger, ha estudiado con inteligencia académica la teoría de los géneros referenciales, advierte que "el interés conceptual por estos géneros parece estar asociado, en su origen, a la crítica de las vanguardias históricas (primeras décadas del siglo XX) al principio (ideológico) de la 'autonomía' del arte, es decir, al cierre de la obra sobre sí misma como orden estético y cognitivo, al 'desinterés' que se le atribuye y a su consecuencia inmediata y necesaria: la distancia (separación, diferenciación) que introduce frente a los discursos definidos por sus funciones pragmáticas" ". Si Morales está en lo cierto, y mi opinión es que lo está, podría hipotetizarse que fue la crisis histórica del 73 la que gatilló en José Donoso (y no solo en José Donoso) una crisis estética y que esta novela, El jardín de al lado, es una de las obras, acaso la más valiosa desde el punto de vista teórico, en la que él arregla sus cuentas con la segunda, buscando el modo de encontrarle un desenlace "políticamente correcto", pero no en desacuerdo con las que eran sus convicciones más arraigadas. Para una tentativa similar, en 1978, en Casa de campo, había recurrido a un artificio alegórico, en el que, como lo explica Carlos Cerda, "aparentemente sólo imperan las leyes de la fantasía, pero que produce el efecto de una toma de distancia respecto del objeto de la apropiación literaria para imponernos la captación de sus elementos más significativos" (Cerda 19). Y para ello también es que ahora incorpora en la escritura de El jardín de al lado esas "funciones pragmáticas" de las que habla Morales, coqueteando con la cancelación ficcional que la autobiografía supone, pero por el camino híbrido de una novela autobiográfica

productores y las expectativas de una fracción del público (externo), y, por ende, por una transformación de las relaciones entre el campo intelectual y el campo de poder" (Bourdieu 25-8).

Ibíd. 
a contrario modo o, para ponerlo en el lenguaje de los retores medievales, bajo la forma de un exemplum negativo, el de lo que no se debe hacer ${ }^{7}$.

Como otros de los escritores de la llamada en Chile "generación del 50 ", es sabido que Donoso es, fue, aun en sus obras tempranas, un novelista cuyo discurso estuvo ligado al ideológico de la oligarquía criolla, si bien convencido de que su tarea de escritor consistía no tanto en la narración de sus logros como en la de su ocaso ${ }^{8}$. Frente a los avances políticos y sociales que caracterizaron la gestión histórica del Chile desarrollista, el anterior al golpe de Estado del 73, él fue uno de los escritores que sintieron que las campanas del funeral oligárquico estaban sonando. Con posterioridad al golpe y frente los horrores que desató, recogió él y recogieron los otros las riendas, eso es cierto, pero no para hacerse parte de un proyecto democratizador sino para nostalgizar el eclipse definitivo del orden tradicional, el "orden de las familias", el mismo que Pinochet, supuestamente, habría cancelado de un solo tajo. Eso es lo que ocurre en Casa de campo, la novela de 1978, en la que el capataz desplaza del poder a los patrones y se apodera de la casa. Una novela como Los convidados de piedra, de Jorge Edwards, que es del mismo año, nos suministra una versión que no es muy distinta de ese desánimo oligárquico. La fiesta que constituye su marco es una celebración, la de la derrota de la Unidad Popular, y un sepelio a la vez, el de los oligarcas

\footnotetext{
"Tipo de relato medieval, en latín o en lengua vulgar, cercano por su construcción y finalidades a la fábula o el apólogo. Battaglia lo hace depender del concepto griego de parádeigma, estudiado por Aristóteles, y especializado en el medioevo en el sentido de un relato que tiene un valor ejemplar absoluto, de testimonio o prueba válida para todos los hombres, sin ser en sí mismo, 'ni moral ni inmoral; es sólo una indicación, una muestra del bien y del mal que cohabitan en la experiencia de los hombres' (L'esempio medievale). Welter ( L'Exemplum dans la littérature religieuse et didactique du Moyen Âge) señala que el exemplum es 'un relato o una historia, una fábula o una parábola, una moralidad o una descripción que puedan servir de prueba en apoyo de un discurso doctrinal, religioso o moral [...] tenía que contener tres elementos esenciales: un relato o una descripción, una enseñanza moral o religiosa y una aplicación de esta última al hombre'. El ejemplo alcanza su mayor perfección literaria en El conde Lucanor" "' (Marchese 156).

"El novelista oligarca, o que aspira a serlo, tiende a producir una literatura hegemónica, normativa -icastigo por decir 'rojo' en vez de 'colorado'!-, propia de un mundo que no debe parecer, por ningún motivo, un mundo amenazado. Suelen ser novelas un poco duras, sin oscilación, divertidas, agudas, inteligentísimas, a veces encantadoras, pero carentes de pathos. No tienen esa visión tentativa que propone al autor como víctima parcial de su propio texto, desgarrado por toda clase de titubeos que son, al fin y al cabo, la esencia misma de toda gran novela" (Donoso, Conjeturas 19).
} 
chilenos. En la novela de Donoso, la madre, que se niega a comer y que se extingue poco a poco en su asqueado rechazo del mundo, configura, por eso, el centro de un centro: si el centro del jardín fundacional es la casa de la calle Roma, el centro de la casa de la calle Roma es la madre cuya muerte acarreará consigo la muerte (es decir su venta "a los nuevos ricos de este régimen" [173]) de la casa.

Julio Méndez nos informa sobre la repugnancia que a esa buena señora le ha producido el cierre del Congreso Nacional por los militares y hace que su padre añore desde la tumba el papel que ahí desempeñó: "ese Congreso en que tantos años representé como diputado por una región en que están las raíces de nuestra familia, y encarné un civilizado aunque tal vez injusto liberalismo que por lo menos era ilustrado" (74). En tanto que la viuda, quien en medio de su delirio arterioesclerótico confunde a Allende con Pinochet, fantasea con su marido ya difunto, pero que "hablaría en el Congreso para que Allende no nos entorpeciera la entrada al país" (89). Uno puede discutir lo atinado que pudo ser un diagnóstico tan apocalíptico como ése de Donoso y sus colegas de los años cincuenta sobre el destino de la casta oligárquica a la cual pertenecían por su nacimiento o con la cual se identificaban por voluntad propia (yo, personalmente, pienso que era erróneo o, lo que es peor, que era una pose marginalista que no andaba muy lejos de la del artista rebelde en la modernidad), pero lo que no se puede hacer es poner en duda la riqueza de sus consecuencias estéticas.

Porque Donoso es el gran escritor que Méndez no es y, vista su producción literaria desde la distancia que nos dan los años que se nos han ido desde entonces hasta ahora y cuando los productos de los novelistas del boom se añejan vertiginosamente en la bolsa internacional de las vanidades, él es uno de los pocos que resisten la caída. Llegado tarde a esa fiesta cuando ya "iba por los cuarenta años, pero era autor sólo de dos libritos de cuentos y Coronación" (Donoso, Historia 65), casi como el protagonista de El jardín de al lado, que es autor de dos novelas y un libro de relatos (37), cuando Julio Cortázar, Carlos Fuentes, Gabriel García Márquez y Mario Vargas Llosa ${ }^{9}$ ya habían publicado algunas de sus obras mayores, o haciéndose parte de esa fiesta con un ahínco no demasiado convincente, ni siquiera para él mismo, según se percibe en los pliegues de su Historia personal del 'boom', acabó por ser el anfitrión de una

9 Para Donoso, los cuatro escritores que nombro aquí son los que "componen el gratin del famoso boom". Ibíd. 90. 
fiesta distinta. Tiene un mundo suyo que contar, personal e históricamente enraizado, posee una perspectiva ideológica al respecto, la rastrea con pasión y la proyecta en algo así como un horizonte ideal del que las formas de la ideología constituyen su modelo, pero que no las repite sino que las sublima y eficientemente: un mundo en decadencia, de seres y espacios degradados (el que por lo demás constituye el estímulo profundo de su proclividad esperpéntica), la atribución a ese mundo de un tiempo anterior espléndido, por lo general localizándose la experiencia del mismo en los recuerdos de infancia del individuo que narra, y la construcción con esos materiales de un arte cuya calidad se halla al margen de cualquier discusión. Como reflexiona el narrador que evoca su casa y su familia de la niñez en "Paseo", uno de sus cuentos más famosos: "[éramos, los de la "familia"] gente que estaba destinada a vivir dignamente para después instalarse con toda comodidad en el cielo, un cielo idéntico a nuestra casa", porque "el infierno existía, claro, pero no para nosotros sino que para castigar a los demás habitantes de la ciudad"10. Es pues ahí, en el locus perfecto donde habita o habitó ese niño, en la que no es otra cosa que la casa donosiana por excelencia, piedra angular de su universo narrativo y sobre la que los críticos han derramado litros de tinta, donde el demonio demótico se fue infiltrando poco a poco:

Para mí la casa es el espacio donde ocurre la fábula, donde sucede la novela, el lugar de la acción y la pasión, del orden y las reglas, y del catastrófico, aunque a menudo insignificante, advenimiento del caos (Donoso, Conjeturas 267).

Todo esto forma parte de El jardín de al lado, con el añadido de que en esta novela la figura protagónica, la encubierta apenas, es el mismo Donoso o, dicho con más exactitud, es Donoso que conversa con Donoso acerca de la posibilidad de escribir la "gran novela del golpe", procurando exorcizar con la exposición de los errores conceptuales de su alter ego ficticio los terrores propios. Es el niño-grande de la cita de "Paseo" que yo incluí en la cita de arriba o el de la confesión en las Conjeturas... o el protagonista de Correr el tupido velo, y que también es el narrador de Este domingo, su "novela madre"

$10 \quad$ "Paseo" en El charleston. Santiago de Chile. Nascimento, 1960, pp. 111 y 114-115.

11 Así la califica en el programa de la puesta en escena que hizo ICTUS en 1991 y que está reproducido con el título "Ópticas y avatares" en José Donoso y Carlos Cerda. Este domingo (versión teatral), Santiago de Chile. Andrés Bello, p. 9. 
el que ahora ha sobrevenido el "caos", un terremoto histórico de dimensiones colosales, que destruyó lo que aún quedaba en pie de la perfección de su casa y que lo ha obligado a fijarse en "los demás habitantes de la ciudad" e invitándolo incluso a hacer causa común con sus desventuras, por lo cual está pagando el precio que sabemos. Poco importa que el grupo social al que ese individuo pertenece haya sido cómplice activo del descalabro. Él no lo fue, y por eso está en el exilio, un exilio que pudo constituirse en el motor de su éxito, en la medida en que le estaba despejando un camino que de tomarlo lo hubiese sacado de su sequedad ideológica y trasladado a la práctica estética, pero que en cambio se está constituyendo el motor de su ruina:

Vuelvo a la máquina. La miro con repugnancia: un placebo. Un sucedáneo de la exaltación insublimable que me hace permanecer tieso y como embalsamado en mi silla frente a mi trabajo inútil (111).

Y esa ruina es la que Donoso se ha propuesto exorcizar.

Para Donoso, el problema consiste, por lo tanto, en ser y no ser como Méndez. ¿Cómo responder a las urgencias de la historia no siendo infiel para consigo mismo, para con una apuesta literaria que era la de toda la vida? Por otra parte: ¿cómo seguir escribiendo novelas experimentales, del tipo de $E l$ obsceno pájaro de la noche, mientras que en Chile Pinochet y la DINA (o la CNI, lo mismo da) persiguen, encarcelan, torturan y "desaparecen" a sus opositores, cuando el país es una herida abierta y cuando de un total de once millones de habitantes han salido ya un millón con rumbo al exilio?

Tortura, injusticia, derechos humanos, sí, desgarrador, es necesario tomar parte en esa lucha. Pero a mi modo, por favor, a mi modo... (208).

Uno se acuerda, y cómo no, de la célebre frase de Adorno, cuando en Crítica, cultura y sociedad éste afirmó que "Escribir poesía después de Auschwitz es un acto de barbarie". En el último análisis, una tesis como la que involucra esa sentencia adorniana significaba para el escritor, para cualquier escritor y en este sentido Donoso no es más que uno entre muchos, abandonar la práctica de la literatura de imaginación y reemplazarla o por un silencio culpable o por una escritura referencial e instrumental. Escritura denotativa, militante, didáctica, que con la presunción de estar entregando un conocimiento válido acerca de "la verdad" del mundo se aboca a dar testimonio y denunciar, a exhibir y repudiar. "Documental" es el adjetivo que Méndez utiliza para nombrarla y 
yo mismo la he caracterizado en otro sitio como "representacional ingenua", la de los convencidos de que "el lenguaje de la literatura no es diferente de otros lenguajes", que por eso puede dar cuenta de lo real de la misma manera que ellos, y que se opone a la de los que por el contrario están seguros de que "el lenguaje literario es esencialmente diferente de los otros lenguajes y su 'diferencia', la 'específica' nada menos, consiste precisamente en el hecho de que eso que el lenguaje literario representa no se encuentra fuera de él”. Era una falsa disyuntiva, en mi opinión, en tanto el lenguaje de la literatura, el de la buena literatura, si bien es cierto que no nos entrega la realidad de una manera directa, tampoco deja de hacerlo, pues mediada, connotativa o metafóricamente "nos remite al mundo real, lo que tiene que ser asi porque de otra manera el texto literario se aleja parcial o absolutamente del horizonte de nuestra comprensión, esto es, nos resulta paulatinamente ininteligible". Además, "la literatura es o puede ser el instrumento de una cierta verdad del mundo. Esa verdad no es ni puede ser la verdad (al menos, intencionalmente) verdadera del lenguaje cotidiano ni menos aún puede ser la de la ciencia, sino que es la verdad confusa de la que habló Kant o la verdad verosímil de la que hablaron Platón y Aristóteles" (Rojo 192).

Por lo menos en parte, Méndez fracasa porque cae abatido por el maniqueísmo simplificador que hace presa del campo literario chileno en esos años de crisis y que aún no ha hallado el camino para su recomposición. Y si Donoso triunfa, ello se debe, también en parte, a que se desentiende de esa crisis o, mejor aún, a que la neutraliza a través de una práctica que huye de las reducciones abstractas y escarba en cambio en el magma heteróclito de lo particular y concreto. Si Méndez no quiere ser Salvatierra y menos aún quiere ser Adriazola y se empantana y ahoga en esa doble resistencia, habiendo palidecido en él su voluntarista "sentido de misión" (161), pero sin poder salir de ahí, Donoso da el paso que sigue, el que transforma la ideología o, más precisamente, el que se revuelca en ella de una manera tal que acaba produciendo con su sucia materia una obra de arte. Por eso escribe El jardín de al lado y las tres o cuatro novelas que vinieron a continuación.

Indiqué más arriba que El jardín de al lado tenía dos finales. El primero es el del frustrado descenso a los infiernos al que ya me referí, cuando Méndez, después de recibir el rechazo de su segundo manuscrito por parte de Núria Monclús y cierto ya de su "derrota", roba un cuadro de su amigo Salvatierra, lo vende y parte con su mujer a Tánger, un Tánger literario por cierto, el de Charles Boyer y Heddy Lamar (que no era Tánger, sino Argel), el de Barbara Hutton, el de Paul Bowles, el de "la palmera de Matisse pintada desde el 
balcón del Hotel de France" (231), el de R. D. Laing (que no era Tánger, sino Ceylán), el del "legendario encuentro" de Andre Gide con Oscar Wilde "en un café en la cima de la ciudad" (236), etc. Ahí, entonces, en esas calles, que son (¡y dale!) las "de Diáguilev, de Falla, de Tiffany, de Ravel, de Belmondo" (238), trata de repetir lo que de ellos aprendió:

Los ojos transfigurados por el kohl de la mujeres de rostro oculto, y de los muchachitos esbeltos y sobreexcitados por la noche que los espera, sonríen con descaro invitador. La juventud tiene un prestigio de mercancía en estos países, le explico a Gloria para justificar esas miradas y ciertos gestos procaces que no pasan inadvertidos: en Madrid ningún muchacho se dignaría mirarme, mientras que aquí, en cambio, mi aspecto respetable, intelectual, los despojos de mi desplante de clase, que es de lo poco que no se pierde con la edad y el fracaso, se traducen para ellos en poder, fuerza, autoridad, experiencia, sabiduría: por eso no les soy indiferente (234).

La reversión de papeles es clara: el chileno derrotado en Europa, además de ladrón, es "aquí" (el deíctico se repite insistentemente), en "estos países" y en virtud de su (por desgastado que esté) "desplante de clase", un europeo victorioso, apetecible, pero sobre todo desconocido:

Aquí nadie puede leer la vergüenza en nuestras expresiones, como en Santiago podrían leerla igual en Providencia que en el barrio de La Vega. ¿Cómo adivinar, aquí, quién es qué, qué significan esas miradas desde el fondo de los capuchones, qué forma tienen y a qué clase económica y cultural pertenecen esos cuerpos escondidos por la lana tosca de sus cache-misère? Es fácil perderse para siempre, aquí: la idea es seductora, porque significaría, en esta muchedumbre dorada por la electricidad titubeante de los bazares, asumir otra moral, una moral que no obligue a confiarle mis humillaciones a Gloria [...] ¿y si yo aprovechara su desatención para hundirme para siempre en esa callejuela tenebrosa, empinada, angosta, torcida, perdiéndome para siempre en la noche vertiginosa de los bazares para renacer al otro lado, con una moral inversa? (237-238).

Sale Méndez eventualmente en busca de la experiencia del "hundimiento", de la "perdición" y del "renacimiento" en la "noche vertiginosa" del Kasbah, y solo sabemos de los resultados de su aventura en el segundo final de la novela. Muchos factores se asocian con ese acto de Méndez, reivindicativos, literarios, sexuales, etc., pero en lo esencial se trata de una nueva tentativa 
de sublimación, pero apelando esta vez al polo opuesto y demoníaco del paradisíaco del jardín de al lado:

no puedo dejar de sufrir el tirón de lo repulsivo de estas calles que me sacude con el ansia de desdoblamiento: es idéntica, aunque inversa, a aquella ansia que sentí frente a una remotísima ventana verde sobre la piscina de un palacete, donde muchachas y muchachos diseñados por Brancusi -especialmente una, su cabeza estilizada en la forma de una campana de oro- bailaron junto al agua, bajo el ciprés, aquella noche (238).

Pero así como allá fue solo un voyeur, se entiende que tampoco acá supere ese estadio: el infierno del Kasbah no es sino el jardín de al lado puesto patas arriba y el mendigo que ocupa su centro no es sino la contracara de la dorada (¿anda por ahí La fille aux yeux d'or, una nouvelle de Balzac sobre la homosexualidad femenina, y a la que increíblemente el sobrecargado catálogo culturalista de Donoso no consulta?) condesa de Pinell de Bray:

Como todos, viste su chilaba de lana parda -el cache-misère que nada esconde- y el capuchón sobre su cabeza aporta un séquito de sombras: de ellas, sin embargo, mi mirada rescata un finísimo perfil, una joven barba rala, dos ojos donde reluce sin fuerza ese bello agotamiento sensual y dorado que a veces uno encuentra tanto entre la gente del Rif como en las invenciones de Klimt bajo los arrayanes de cierto jardín tan vedado como esta callejuela (240).

A "muchos kilómetros y a muchos meses de distancia de esa noche en el Hotel Minzah" (250-251), Gloria es quien toma la palabra finalmente, para aclararnos lo que aconteció efectivamente y para aclarar además que ella es el autor de la novela que acabamos de leer, que siempre lo fue. Ella fue el autor implícito, ése al que nosotros sentíamos manipulando a sus muñecos por detrás de las cortinas del teatro donosiano, que ahora se torna en autor explícito y que también asume el papel de narrador. Núria Monclús está dispuesta a publicar su manuscrito, según le ha dicho a Gloria, pero exige que ésta le introduzca el segundo final, o sea que le exige a Gloria que se autoidentifique como quien ella es dentro del entramado de posiciones que organiza a los puntos de vista en el espacio narrativo. La intención de Monclús es efectista y comercial, evidentemente. Hay, sin embargo, en esa exigencia de que se pongan por fin las cartas sobre la mesa una cierta lógica que excede a la del puro golpe de efecto y afán de lucro. No solo porque 
la historia narrada es, ha sido, la de uno que se mira a sí mismo como el novelista que quiso ser y no pudo y de otro que desde la sombra lo mira autoflagelarse y se ríe de él -una perspectiva doble a la que ahora parece conveniente disasociar-, sino porque en el desenlace se le está entregando este último poder a una mujer que no lo buscó y a la que en ningún momento se pensó como digna de tenerlo ${ }^{12}$. He aquí el nacimiento de su novela en las palabras de Gloria:

Alrededor de esa fantasía [la del jardín de la Pinell de Bray], a nuestro regreso aquí, comencé a llenar cuadernos y más cuadernos con mis lamentaciones y conjeturas. Y cuando Julio me dejaba sola para acudir a su trabajo, me di cuenta de que, así como no podía exigirle todo a él, yo tampoco podía exigírmelo todo a mí misma. Escribí mis quejas en mi diario, tan desgarrador que ahora no me atrevo a releerlo; pero al releerlo entonces para escarbar en mi rencor, y al volver y volver a escribir esas páginas, y darles vueltas y más vueltas, fui como depurándolo todo, en ese tiempo tan largo que las estaciones han obsequiado junto al Mediterráneo, depurando la imagen de mi misma, la de Julio, la de nuestro matrimonio, hasta darme cuenta de que para que este examen tuviera fuerza de realidad era necesario que yo construyera algo fuera de mí misma, pero que me contuviera, para "verme": un espejo en el cual también se pudieran "ver" otros, un objeto que yo y otros pudiéramos contemplar afuera de nosotros mismos, aunque todo lo mío sea, ahora, en tono menor (254-255, el destacado es mío, G. R.).

Es pues Gloria, la "otrora perfecta Odalisca de Ingres" (26), la que "jamás tuvo pretensión de ser una "creadora" (39), la que lee "libros de quiromancia" y prepara un "estudio sobre la discriminación sexista en las ciencias ocultas" (23), ridiculizada y despreciada hasta el cansancio por su culto marido, y no éste, quien sale al cabo con un domingo siete. Ella puede hacer en "tono menor" lo que el otro no pudo ni podrá hacer jamás en "tono mayor": sublimar su abyecta miseria ideológica convirtiéndola en una preciosa obra de arte. Ella es, en fin, el escritor José Donoso. 


\section{BIBLIOGRAFÍA}

Bourdieu, Pierre. "El campo literario. Prerrequisitos críticos y principios de método". Trad. Desiderio Navarro. Criterios, 25-28 (1989-1990): 4.

Cerda, Cerlos. José Donoso: originales y metáforas. Santiago de Chile: Planeta, 1988. 19.

Donoso, José. El jardin de al lado. Madrid y Bogotá: Espasa Calpe y Planeta Colombiana, 1981. 32-33.

Conjeturas sobre la memoria de mi tribu. Santiago de Chile: Alfaguara, 1996, p. 19. "Paseo". El charleston. Santiago de Chile: Nascimento, 1960. 111 y 114-115.

Donoso, José y Carlos Cerda. "Ópticas y avatares”. Este domingo (versión teatral), Santiago de Chile: Andrés Bello, p. 9.

Gutiérrez Girardot, Rafael. "El arte en la sociedad burguesa moderna”. Modernismo. Supuestos históricos y culturales. Bogotá: Fondo de Cultura Económica, 2004. 54.

Marchese, Angelo y Joaquín Forradellas. Diccionario de retórica, crítica y terminología literaria. Barcelona: Ariel, 1998. 156.

Montero, Oscar. "El jardín de al lado: la escritura y el fracaso del éxito". Revista Iberoamericana 123-124 (1983): 450.

Morales T, Leonidas. La escritura de al lado. Géneros referenciales. Santiago de Chile: Cuarto Propio, 2001. 11.

Rojo, Grínor. “"Epílogo nostálgico. La identidad y la literatura" en Globalización e identidades nacionales y postnacionales..., ¿de qué estamos hablando? Santiago de Chile: LOM, 2006. 192 et sqq.

Valdés, Adriana. "El jardín de al lado". Mensaje 301 (1981): 431-432. 